\section{NZNSEE 1997 CONFERENCE Feature Session on Last Decade}

\section{Report by David Hopkins, Session Chairman}

\section{KEYNOTE PRESENTATIONS}

A rare concentration of experience and specialist expertise in a number of fields was available. Each had been asked to prepare a paper looking at the last ten years in a particular field of earthquake engineering and to summarise their thoughts in a 12 minute presentation. The result was an unparalleled distillation of developments and issues over the range of topics along with the opportunity to ask questions.

All papers will become landmarks in their fields, each being a valuable source of relevant references and a brief review of achievements to date.

Presentations were made by:

\author{
Professor Euan Smith - Seismology \\ Professor Michael Pender Geotechnical Engineering \\ Rob Jury - Buildings \\ Professor Bob Park - Bridges \\ Bruce Shephard - Risk and Insurance \\ David Brunsdon - Lifelines
}

The presenters did an excellent job of condensing their presentations to meet the time available and to make them interesting. The question and answer session had to be extended beyond the programmed time and could well have gone on for another hour.

This report is not an attempt to summarise what were already condensed presentations but simply to highlight some of the issues raised by the presenters and from the floor, and to point up some questions which were raised either at the time or in response to the session. The full texts of the presentations is given elsewhere. Key points made were

\section{Euan Smith - Seismology}

- Improved instrumentation network including in structures giving digital record.

- New Zealand modellers are world leaders.

- Achievement in microzonation of sedimentary basins.

- Recognition that earthquakes are a multi-discipline hazard e.g. lifelines.

- $\quad$ Attenuation progress but more work need on reasons for scatter (sensitivity to geological strata/forms).

- Updating of seismic hazard model - information for the next generation of models is now available.

- Information from major earthquakes in New Zealand and overseas.

- $\quad$ Development of NZ MMI Scale

Michael Pender - Geomechanics

- Mexico 1985 to Kobe 1995, a key decade.

- Mexico City earthquake changed things.

- $\quad$ Research into response to strong motion as against weak motion.
- Magnification in after shock of Loma Prieta versus no magnification in main event.

- Quality information from major earthquakes.

- $\quad$ Large amounts of data are now being generated.

- Kobe earthquake provides information on damage due to liquefaction and settlement.

Rob Jury - Buildings

- Regulatory changes

- Building Act/Codes

- Joint Australian.New Zealand Code

- $\quad$ Emergence of displacement based methods of design.

- $\quad$ Structural precast concrete - Study Group publication.

- $\quad$ Existing buildings - two Study Groups and publications of draft recommendations.

- Use of special systems e.g. base isolation.

- Development of code for building contents.

Bob Park - Bridges

- $\quad$ Pioneering work on seismic design of bridges was conducted by a study group of NZNSEE and published in 1980.

- Design Spectra - not safe at low periods for structures requiring large ductility.

- Displacement based design is more logical.

- $\quad$ Capacity design - must be used to prevent shear failures.

- $\quad$ Confinement effects - more known. Importance heightened.

- Lead rubber bearings - widely used and exported

- Retrofit and assessment of bridges becoming an issue. ( $80 \%$ of current bridges built before 1970 .)

Bruce Shephard - Risk and Insurance

- Graphic data on recent insurance losses

- Climate of overseas losses, changes in government approach in NZ including the Resource Management Act 1991, led to an upsurge in assessments and loss studies.

- There has been extensive quantification of potential loss and of risk.

- $\quad$ Asset management plans equals risk management.

- Use of GIS vital to such studies - has enhanced methodologies.

- Four important conferences in NZ,

- Confidence levels in figures need examination.

- $\quad$ Continued development of natural hazard and loss data basis is needed

David Brunsdon - Lifelines

- $\quad$ Coincidence of risk management and insurance with Lifeline projects.

- $\quad$ Presented a timeline showing the development of Lifeline projects over the decade and highlighted the recent expansion.

Presented examples of mitigation in NZ - an encouraging sign.

- Development of response planning amongst TA's. This provides linkage between public and private utility organisations and emergency management agencies. 
- A wider view of seismic risk has been developed.

- $\quad$ NZ has benefited from good relations with US and Japan.

- Summarised factors which have been critical to the success of Lifelines Earthquake Engineering in the last decade.

\section{DISCUSSION SESSION}

Ron Mayes asked about the effect of near-fault events and the need to allow plenty for displacement, especially in base isolated buildings. He suggested that the allowances made in recent Wellington buildings such as the New Zealand Houses of Parliament may not be adequate.

Les Megget pointed to the importance of structural forms, and observed that irregular buildings are still being produced.

Nigel Priestley asked the question of all presenters as to what they would like to see happen in the next decade. This produced a most worthwhile discussion and the following topics were mentioned as requiring attention:

building services;
detailing of connection of tilt-up concrete panel
elements
ductility - how to achieve it. What it means to
building performance;
community response to earthquake;
design methods e.g. performance based design;
promotion of awareness amongst architects;
owner/engineer expectations of damage (need to be
reconciled);
underground services/lifelines;
analysis and assessment of the performance of
- $\quad$ - $\quad$ wisting buildings and determination of what to do
achieving the intended standards in the finished job
- $\quad$ (i.e. implementation).

Other comments/questions included:

- $\quad$ An over-emphasis in structural design on providing sufficient lateral strength at the expense of understanding how the building as a whole is likely to respond.

- There remains a definite need for consistent marrying of hazard models derived from geological bases (i.e. faults) with those obtained from current seismicity (i.e. recent history)

- $\quad$ How well do clients (particularly building owners) understand that ductile structures, although surviving severe earthquakes, may be badly damaged? Answer: Not well, and owners are becoming increasingly concerned about property damage.

- How well are hazard maps being utilised in mitigating risk? Answer: Reasonably well. They are playing their part, but greater awareness and promotion of the benefits is needed Development of country wide coverage should continue.

- The development of useful design methods for direct application in design offices. structural performance.

The development of new methods for improving

- The practical and cost issues associated with obtaining basic information from the Institute of Geological and Nuclear Sciences.

- Performance of building services and contents in earthquakes is important, particularly with respect to Occupational Safety and Health.

- More research is needed on the effects of earthquake on industrial plant.

\section{THE NEXT DECADE - Some Suggestions and Challenges}

The session was intensely stimulating and many thoughts, and suggestions arose at the session, and in subsequent informal discussions. Here are some resulting thoughts, suggestions, and one or two challenges for the next decade. May they stimulate many more as time passes, and may effective action result.

a) Seismology

- $\quad$ Every opportunity must be taken by earthquake professionals of all disciplines to underline to funding agencies the vital importance of research into the seismology of New Zealand. It is the foundation on which all other research (and implementation) is built. And yet, it is the hardest to justify using the prevalent short-term funding criteria.

- We have a good network of instrumentation. How about mounting some automatically triggered video cameras which can record the response of surrounding structures?

- More research is needed on parameters which account for the effect of duration of earthquake shaking on damage and building/structure performance. This will require co-operation with other disciplines, notably geotechnical and structural.

- Are there sufficient co-operative/exchange programmes between New Zealand and US/Japan? Are we making as much of the existing NZ/US Science and Technology Co-operation Agreement as we could?

Seismologists who put together design spectra and seismologists who deal with 'straight' seismology need to gain a better understanding of each others work.

\section{b) Geotechnical Engineering}

In this largely empirical discipline it is hardly surprising that the major earthquakes of the last decade have produced a wealth of information for researchers and practitioners.

The nature of the non-linear response of soils according to input intensity has a crucial effect on structures and the built environment. Clearly the next decade will see more developments in this area. Research on this topic should attempt to quantify the effect of sedimentary soils on the duration of shaking, not simply peak intensity of acceleration, velocity or displacement. 
As owners of assets in New Zealand become increasingly conscious of their responsibilities to manage risk, we can expect increased interest in geotechnical aspects over the next decade.

Geotechnical engineering has a fundamental role in the assessment and design of lifelines for earthquake. Encouragement of our researchers is required to become more involved in lifeline earthquake engineering.

c)

\section{Buildings}

The role of capacity design of buildings for earthquake continues to increase in influence and could perhaps be the single most important mitigation factor (when correctly implemented) of the past decade and several future ones.

Rob Jury's remarks on the need to provide symmetry and reliable load paths have a familiar ring! They have been made by others before and will regrettably be made on future occasions. How can we break the cycle of "lessons relearned" in each new earthquake. We need to focus more on these fundamentals than on developing ever more voluminous codes (actually A4 size text books!). New Zealand's concrete code is 250 pages - the commentary is another 250 pages. Does such verbosity provide understanding and appropriate action, or simply convey the wisdom and understanding of code committee members?

The 11th World Conference on Earthquake Engineering saw several entreaties by developing countries to help them make simple structures safer. New Zealand earthquake engineering researchers and designers are well placed to respond by focusing more attention on these pressing issues.

We must learn more about the expected performance of existing buildings so as to build our confidence in assessments of the risk they represent. We can expect significant action on this over the next decade, particularly in the testing and analysis of structural forms used in pre-1975 buildings. Future research must throw more light on the relationship between the elemental response and that of the whole building.

\section{d) Bridges}

Here, too, capacity design has made a key contribution. The events of Northridge and Kobe highlighted the importance of deck continuity and ductility of piers. Assessment of risk for existing bridges will continue, and doubtless pressures on funds will force hard decisions on priorities for mitigation. Earthquake engineers in this field, as in all others, need to be in a defensible position after the next large earthquake in New Zealand.

The proven benefits of deck continuity highlight the need to regard a bridge as a total structure, including piles and soil structure interaction. This will bring into sharper relief any effect of earthquake wave propagation on long bridges.

\section{Risk and Insurance}

It seems unlikely that the next decade will produce such significant developments as the last, but interest may be expected to continue. The combination of circumstances which led to an upsurge of interest in New Zealand saw a welcome increase in awareness of earthquake risk and the role of insurance as a tool in the risk management of assets.
Development over the next decade will depend on continuing development of databases. Increased understanding and quantification of the earthquake hazards will continue which will require having systems in place to record and quantify earthquake damage and loss data.

The dazzling computer techniques now at our disposal have made very detailed analysis possible. Moreover, clever GIS presentations have greatly enhanced our insight into the issues. In turn this has allowed better use of resources for mitigation. Unfortunately, the wide confidence limits inherent in some input data (e.g. damage ratios) are lost on many who attribute an unfounded precision to the results. Hopefully, the next decade will see precision to the results, narrowing band widths of confidence in raw data and more realistic interpretations of the results.

f)

\section{Lifelines Engineering}

David Brunsdon's paper highlights an extraordinary development over the last decade (actually only 8 years!). A combination of increased awareness of earthquake risk, overseas events, and the strong technical and moral support of US and Japanese colleagues led to these noteworthy achievements and sustained interest.

Some fundamental research work is needed to interpret the behaviour of lifelines by adapting and extending overseas research to match New Zealand conditions. The next decade will see progress here as well as in more widespread mitigation.

Development of codes of practice and/or design guides for lifelines in earthquake looks likely to receive attention in the next decade. Input from practitioners, asset managers and geotechnical researchers will be needed.

The development of response planning aspects may be expected to continue and the Emergency Services Review will bring fundamental changes in the way New Zealand organisations respond to a major earthquake. It is hoped that full advantage will be taken of the response planning work stimulated by lifelines earthquake engineering, not to mention the lessons thrown up by Loma Prieta, Northridge and particularly Kobe.

\section{CONCLUDING COMMENTS}

It is impossible to generalise over such a wide range of topics. Three things stand out, however:

a. New Zealand is fortunate in having tremendous cooperation and ready interaction between professionals involved in the various "disciplines" working on the common goal of mitigating earthquake risks.

b. A better measure of the damaging potential of earthquakes is needed. Such a measure needs to reflect seismological, geological, geotechnical and structural aspects in a holistic way. In particular, factors influencing the duration and intensity of response need to be determined.

c. There is an increasing divergence between the sophisticated approaches of developed countries and that of developing countries where knowledge and data on earthquake engineering is much less sophisticated. 
And yet the centre of gravity of global earthquake risk lies well within the developing countries and is settling ever more firmly in that position. This fact is not reflected in the balance of published research in earthquake engineering.

The next decade must build on the perspectives available from IDNDR and accord developing countries their due attention in education, research, design and implementation. In this age of globalisation such action is the responsibility of all involved in earthquake engineering wherever they happen to live. 